\title{
The Research on Spatial Forms of Hathpace Folk Houses
}

\author{
Liu Jing \\ School of Civil Engineering and Architecture \\ Xiamen University of Technology,Xiamen,China \\ 308113090@qq.com
}

Keywords: The hathpace folk houses, spatial structure, spatial analysis, protection

Abstract: The hathpace folk houses in Kashgar are the only one that are preserved well in China today and are also the essence of modern Islamic culture. The unique spatial structure of hathpace folk houses are not seen in other provinces and cities of China. This construction community has strong growth and vitality power. The hathpace folk houses are rich in locality and particularity. They are living and have multiple research values in architecture, history, aesthetics and society.

\section{Introduction}

Kashgar is a historical and cultural city which is once the important town of the ancient Silk Road and is also a place where Western culture, Uighur culture and Islamic culture are integrated and displayed. It maintains architectural art with distinctive regional features and is the most important birthplace of modern Uygur culture. The ancient city is one of the westernmost cities of China. In the northeast corner of this ancient city, the only hathpace folk houses is preserved well in China. It is the essence of the ancient city in Kashgar and is called the 'Uygur Folk Museum'.

\section{The hathpace folk houses are the only one well-preserved high-platform building complex}

The hathpace folk houses are built by the topography in the northeastern part of old town on a high cliff with loess which is over 30 meters high and more than 400 meters long. It has a history of more than 600 years. It is a Uighur settlement based on nature, geography and life needs.So far, many residential dwellings have gone through the 6th and 7th generations. On the high cliff, centuries-old homes are everywhere. Although the hathpace folk houses are also traditional Uighur dwellings, the integrity of their preservation can not comparable with other old town area of Kashgar. (Figure 1)

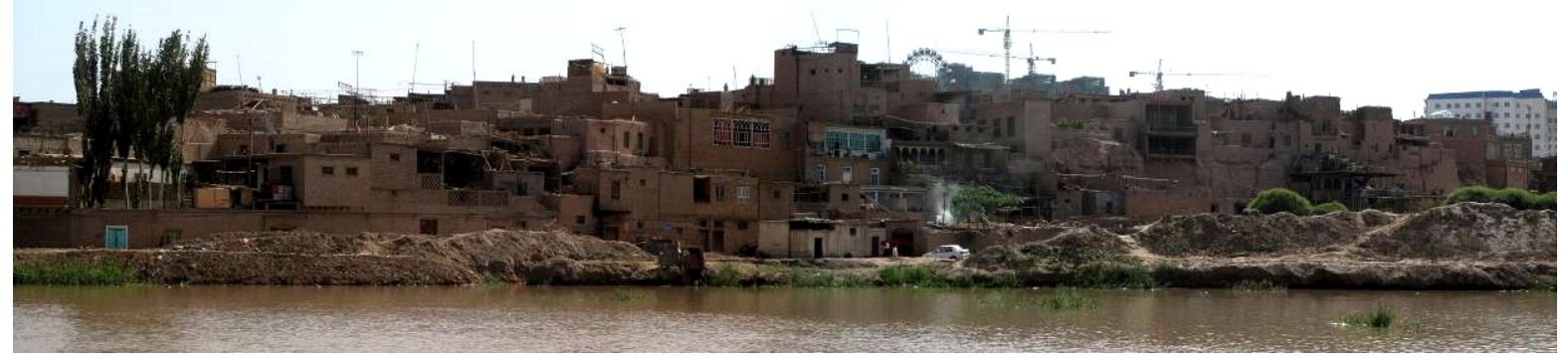

Figure 1 Northeast view of the hathpace folk houses

The hathpace folk houses in Uyghur's language: 'kuan-zi-qi-ya-bei-xi-xiang', which means earthenware pottery on the high cliff, named after the Uyghur millennium pottery workshop. Residents all are Uyghurs, mainly engaged in Uighur traditional handicraft production in Kashgar 
and never lived together with other local people. Here is a concentrated expression the Uyghurs' ethnic and life characteristics and the deep Uyghur's ethnic culture and history. ( figure 2)

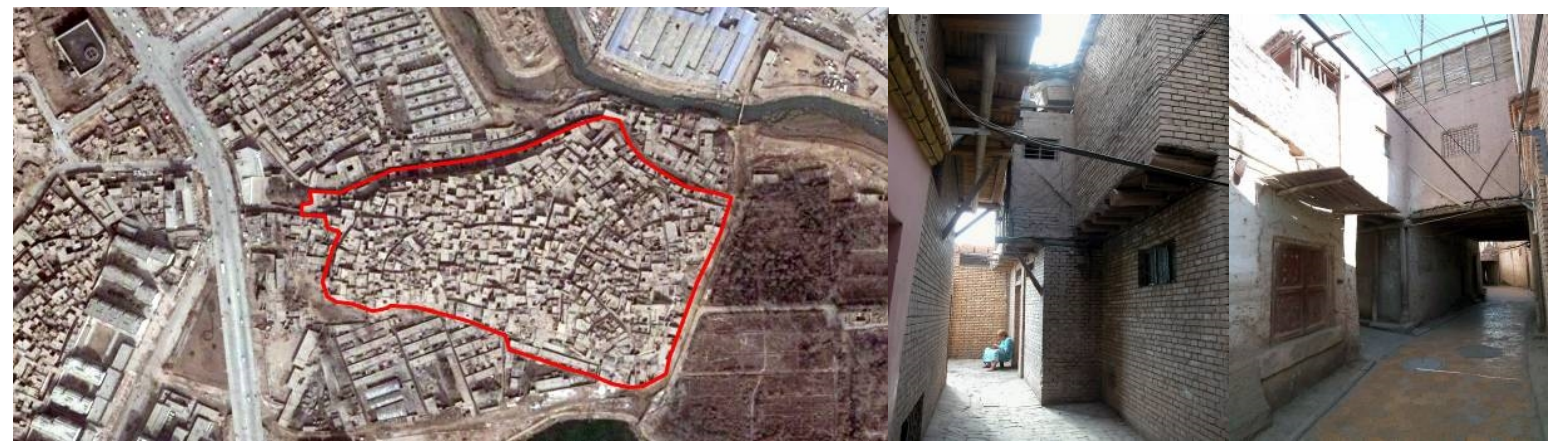

Fig. 2, Plane status of the hathpace folk houses

Fig. 3.4, winding streets and lanes

\section{(1) The growth of the texture of building complex}

The hathpace folk houses show growth continually and the density of buildings is very large. Since the lane ways on the early hathpace houses are all used as drainage channel. there are no artificial plans for the roadways and they conform to the natural terrain and are free to extend. In Kashgar, the climate is dry and hot, so the residents lives nearby the water. Gradually, the residential communities are built on the slopes of high cliffs, forming a layered structure and irregular spaces on the front and back, left and right, above and below. (Fig. 3.4)

\section{(2) The extension of street space}

In Kashgar, the land is flat and weather is windy. For the purpose of preventing winds, the hathpace residential communities have clear edges, few entrances and exits. Internally, except several major roadways, the other roads whether main roads, secondary roads, neighborhood roads or alleys, all of them are T-shaped or end-of-the-line. There are few crossroads. The roadways are mostly 1-3 meters and very narrow and meandering, also the elevations change on the facade. Not only the buildings on both sides are staggered due to topographic relief, but also the roadway ground are followed by steps or gentle ramps. The effect of landscape is extremely rich and varied.

\section{(3) Spatial layout of the courtyard grows freely}

Due to the tense space, in order to expand the space, the houses are extended to the high altitude. An additional floor is built on the original house, and even two floors is added. When the population with a large number, it is not enough space for the residents. Then when the second floor is renovated, creatively, the cantilever of building across the streets to build on the opposite house to expand the area. After several hundred years, the unique 'cross-street building' landscape in Kashi alleyway has gradually formed. The ingenious point is that it does not affect the pedestrian walking on the downstairs and also the residents living on the upstairs. (Fig. 5) It is a kind of building with maximum use of space in a limited range, which can be said the main characteristics of the hathpace folk houses.

\section{(4) Simplicity of external wall -the first impression}

In Kashgar, the maximum temperature in summer can be reached to $40^{\circ} \mathrm{C}$ and the minimum temperature in winter is about minus $22^{\circ} \mathrm{C}$. The residents use local abundant clay as materials, creating the earth architecture with an unique style. The thick external wall $(50-70 \mathrm{~cm})$ plays a very good role in heat preservation, cold protection and heat insulation. At the same time, the small and less windows on the thick walls will reduce the strong light injection to prevent the light baking the indoors in large area and also reduce the impact of sandstorms to the indoor environment. The Uighur's architectural building has a small number of bumps on the external walls and the walls are 
simple. All the external walls along the street are made of adobe and put the straw on the walls. From a far view, the entire architectural complex of hathpace is like an ancient town that has been through a thousand years. (Fig. 6)

\section{(5) The extension of living space - the courtyard.}

The Uighur's homes each have their own courtyards. There are various kinds of flowers and plants in the yard. There are cloisters in front of the courtyard and various floral designs are carved on the columns of the corridor. The wooden circle fences with different lengths under the cloister are all made by the carpenters. The 'Supa' in the corridor, covered with carpets, which is the Uighurs' main living space. The residents spend the most time of a day in the courtyard.

(6) The fifth elevation of building - the roof.

In Kashgar, there are seldom rainy, so the roofs are flat and the slope of the roofs are slight. People can store debris, cool dried fruits and sleep on the roof in summer. It is a natural living room. With the increase of the population, the house began to extend to the high altitude. People build a new floor on the original roof. And the new house could also be storied on the original house. Houses were passed from generation to generation and every home is stacked up layer by layer. (Fig. 7)

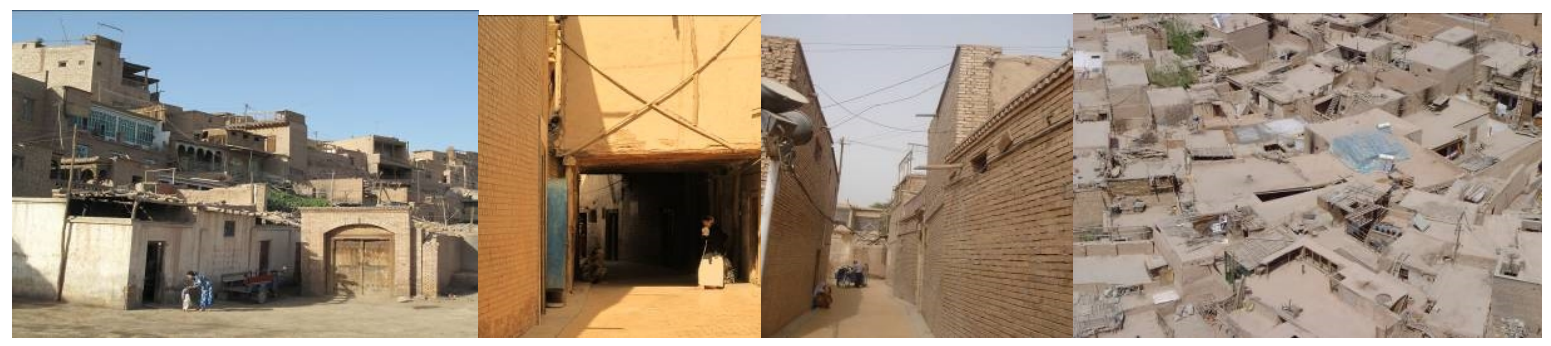

Fig. 4 layered architectural space Fig. 6 the primitive external wall
Fig. 5 the gallery under the 'cross-street building' Fig. 7 the useful roof

\section{The analysis of the hathpace folk houses in typical unit}

The centralized units: the spatial layout is simple and the main living space is surrounded the external walls. there is no middle hall or courtyard. And there are few decorations in indoor and outdoor space. It is common in the small-size houses with lower economic capability. (Fig.8)

The enclosed-courtyard units: the spatial layout is arranged around the central courtyard. The open doors and windows of each living room are facing the courtyard. Courtyard's space is the main living place for a family. A variety of flowers and herbs are planted in the courtyard. The atmosphere of life is lively. It belongs to the inside space and It is a normal style in hathpace folk houses. (Fig. 9)

The workshop-style units: The residents currently living in hathpace folk houses mainly work with small handicrafts. In addition to the tourism value of the old town, many residents living along the streets and lanes have reconstruction the ground floor of their own dwellings as a public communication space mainly for hand-made industry and visitors' tour. And the spaces in upstairs are for living. (Fig. 10) 

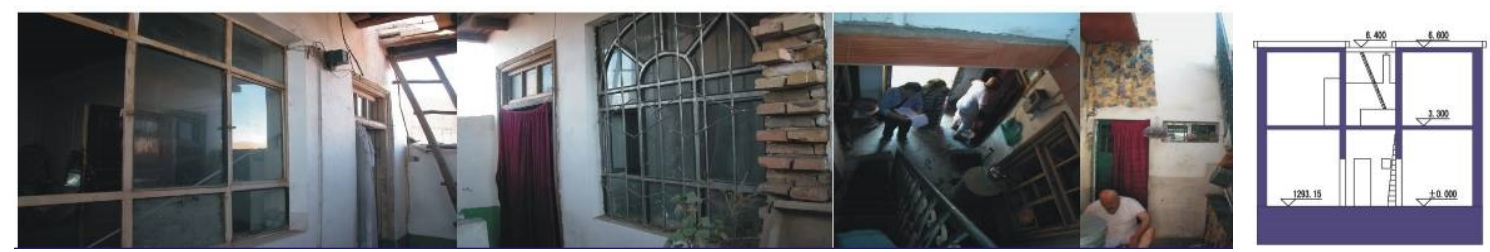

Fig. 8 The centralized units (No.124 houses)

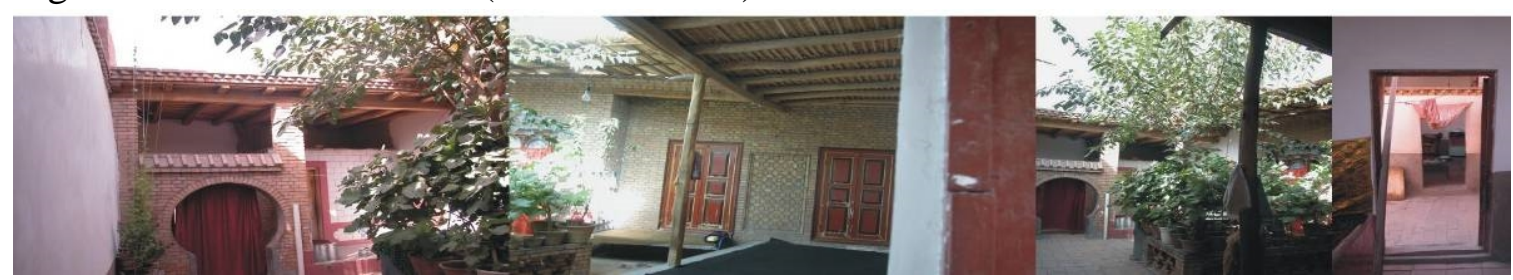

Fig. 9 The enclosed-courtyard units (No.222 houses)

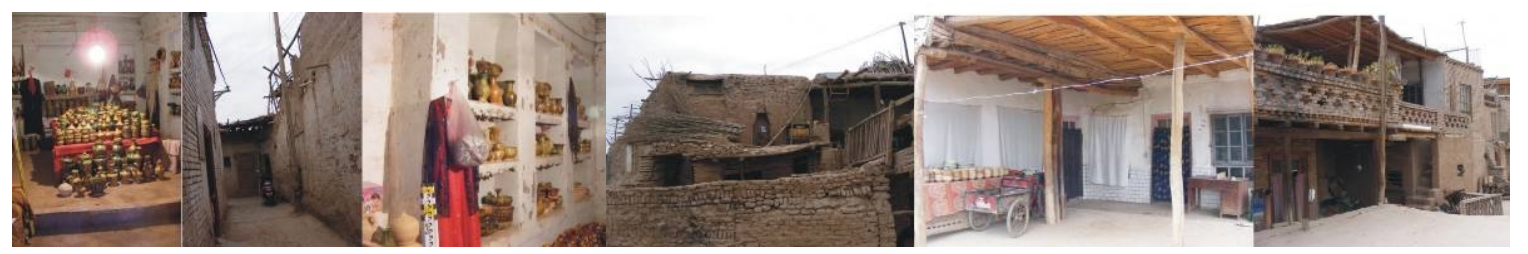

Fig. 10 The workshop-style units (No.531 houses)

\section{The current dilemma of the hathpace folk houses}

Kashgar is in the strong uplifting area of Pamir, The State Seismological Bureau listed 'Wuqia-Kashi' as one of the ten most dangerous areas in China where has a high probability of around 6 degree destructive earthquake. At present, Kashgar has a 8.5 degree earthquake-proof fortification. It is a city in the high seismic intensity area. (Fig.11)

\section{(1) The poor structural stability}

The construction history of hathpace folk houses can be traced back more than 2,000 years ago. However, most of the existing dwellings are built two or three hundred years ago. The housing has been continuously renovated and rebuilt. The early buildings were mainly wood structures with high-quality wooden pillars, wooden beams and earth infill walls. The floors were made of wooden ribs. Most of the external walls along the street were made of adobe and the straw was plastered on the wall. It remains the same during the several ten years or even a hundred years.(Fig.12)

\section{(2) The poor geological stability}

The geology of Kashgar is the self-heavy collapsible loess and its bearing capacity is poor. At the same time, the steep slope zone have been exposed in the surrounding of the hathpace. Existing residential buildings on the original slopes are mostly built follow the slopes. The maximum height of slope reaches 13 meters and the rest most of them are around 6-9 meters. Basically, these folk houses have not undergone any formal design. In existing situation, they are no ability to resist slope slippage, not to mention earthquakes, that is, in normal use, the stability of the slope is not guaranteed and landslides possibly occur at any time. (Fig.13) 


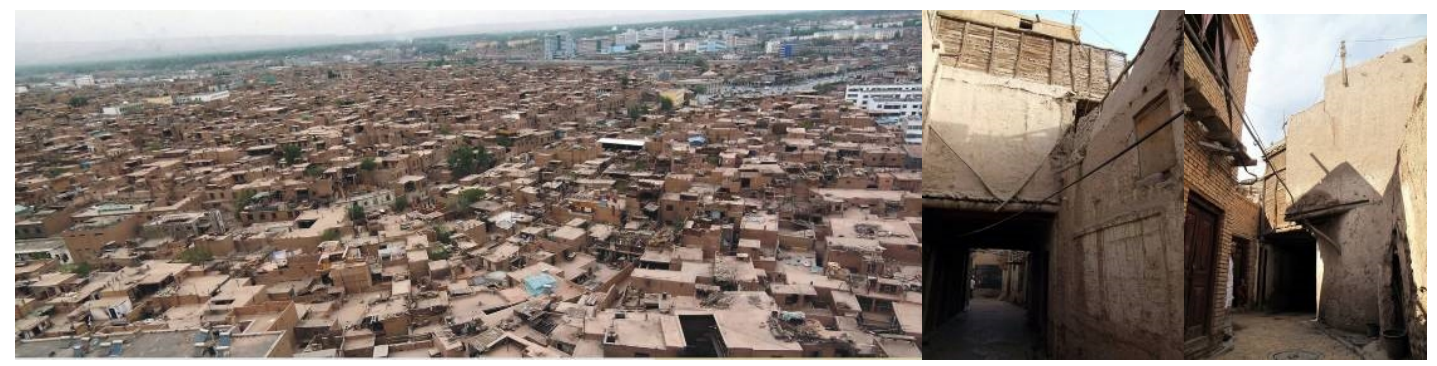

Fig.11 the high-density Kashgar

Fig. 12 the situation of the hathpace folk houses

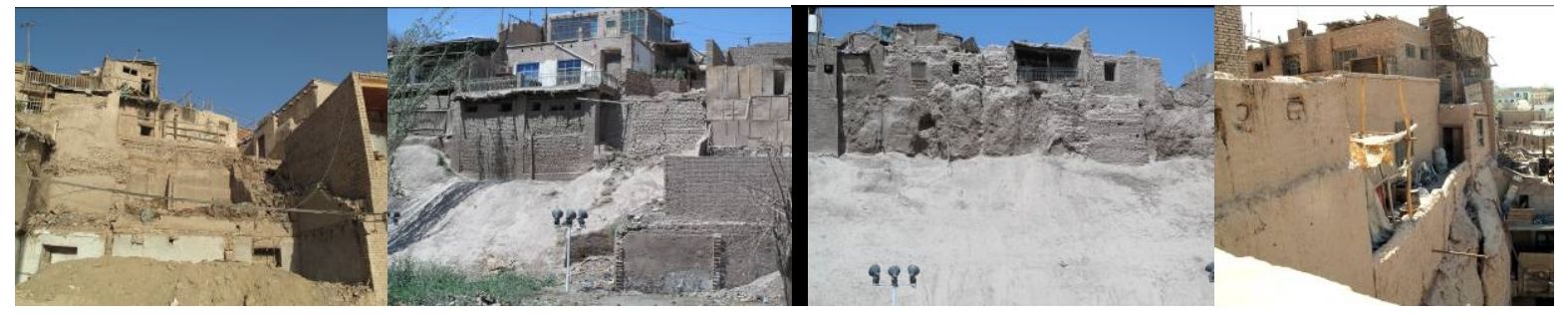

Fig.13 the dangerous slopes

\section{(3) The huge potential safety evacuation}

The formation process of hathpace neighbourhood is very complicated and the time period is very long. After many years of continuous renovation and expansion, the position of each house in the neighborhood is arbitrary and irregular. The streets and lanes are ups and downs, short and long. Many lanes are closed at the end. The channels that can be accessed from all directions are generally about 3 meters in width and 2-3 meters in width at the end of the lanes.They both can't meet the requirements of the fireproof distance and the evacuation road's width. In the emergency, the consequences will be very serious.

\section{References}

[1] Kashgar Yearbook [Z].

[2] ChangQing, The Civilization of Western Regions and the Changes of Chinese Architecture [M],Changsha: Hunan Education Press, 1992

[3] ZhangHong,The Research on the Settlement of Uygur Traditional Cities in Kashgar, Xinjiang [M],Tianjin: Tianjin University, 1996.

[4] ZhaoYu ,Li Jing, An Intensive Settlement in the Old Town of Kashgar - Kashgar's Traditional Uygur Folk Houses [J], Architectural Journal, 1993 (04).

[5] BS Hakim. Urban form in traditional Islamic cultures: further studies needed for formulating theory(J),Cities, 1997, 16(1): 51-55.

[6] Kashgar seismic reinforcement to protect high-profile residential research, 2009

[7] Seismic Retrofit the old city of Kashgar and Environment Protection Research, 2008 